Área Abierta. Revista de comunicación

audiovisual y publicitaria

ISSN: 2530-7592 / ISSNe: 1578-8393

\title{
Hacia una lógica de la sensación. Una lectura deleuziana al cine contemporáneo a partir de Mulholland Drive
}

\author{
Arnau Vilaró i Moncasí1
}

Recibido: 1 de octubre de 2020 / Aceptado: 12 de enerode 2021 / Publicado: 26 de febrero de 2021

Resumen. Para Gilles Deleuze, el cine de Alfred Hitchcock culminaba el cine clásico (imagen-movimiento) al mismo tiempo que asentaba las bases de la modernidad (imagen-tiempo). ¿Qué ha ocurrido desde entonces? ¿En qué medida el vínculo sensoriomotor a partir del cual Deleuze fundamentaba ambos sistemas sigue siendo un mecanismo figurativo para el cine contemporáneo? El siguiente artículo considera que Mulholland Drive ha sustituido el canon estético que, en el cine moderno, fue representado por Vértigo. La hipótesis de este texto es que el film de David Lynch explora la imagen-cristal deleuziana desde lo que el mismo Deleuze, a partir de la pintura de Bacon, llamó una "lógica de la sensación". El desbordamiento de los afectos, la autodestrucción, la pérdida de la identidad, el poder subversivo del deseo o la creencia en un mundo que ya no se conforma con la realidad, son algunos de los elementos que transforman la mirada, la acción y la realidad, ejes principales de la teoría del cine de Deleuze.

Palabras clave: Estética del cine; Cine contemporáneo; Gillez Deleuze; Imagen-cristal; Sensación; Figura; Vértigo; Mulholland Drive.

\section{[en] Towards a Logic of Sensation. A Deleuzian Reading to Contemporary Cinema Through Mulholland Drive}

\begin{abstract}
Gilles Deleuze considered the work of Alfred Hitchcock as the culmination of classical cinema (movement-image) at the same time that he laid the foundations of modernity (time-image). What has happened since then? To which extent is the sensorimotor link on which Deleuze founded both systems remains a figurative mechanism for contemporary cinema? The following article considers that Mulholland Drive has replaced the aesthetic canon that, in modern cinema, was represented by Vertigo. The hypothesis of our work is that David Lynch's film explores the Deleuzian crystal-image from what Deleuze himself, based on Bacon's painting, called a "logic of sensation". The overflow of affections, self-destruction, loss of identity, the subversive power of desire or belief in a world that no longer conforms to reality, are some of the elements that transform the gaze, action and reality, the main axes of Deleuze's theory of cinema.
\end{abstract}

Key words: Film Aesthetics, Contemporary Cinema, Gilles Deleuze, Crystal-Image, Sensation, Figure, Vertigo, Mulholland Drive.

Sumario. 1. Introducción. 2. De Vértigo a Mulholland Drive, o de la mirada al deseo. 3. La pérdida (de la memoria) del sujeto. 4. Hacia una "lógica de la sensación": del régimen fractal de la estructura rizomática a la Figura. 5. A modo de conclusión. 6. Bibliografía.

\footnotetext{
Universitat Oberta de Cataluña (España)

E-mail: avilaro0@uoc.edu

ORCID: https://orcid.org/0000-0002-4698-8363
} 
Cómo citar. Vilaró i Moncasí, Arnau (2021). Hacia una lógica de la sensación. Una lectura deleuziana al cine contemporáneo a partir de Mulholland Drive. Área Abierta. Revista de comunicación audiovisual y publicitaria 21 (1), 45-57, https://dx.doi.org/10.5209/arab.71810

\section{Introducción}

En 2010, Cahiers du Cinéma dedicaba un dossier especial a los mejores films de la década, de entre los que Mulholland Drive -Mulholland Dr., David Lynch, 2001encabezaba la lista. En el mismo dossier, Stéphane Delorme destacaba que "si Mulholland Drive ha creado un paradigma, ha desplazado la referencia de Vértigo-Vertigo, Alfred Hitchcock, 1958- hasta sustituirla [...] es porque sale de la esfera de la memoria y del fantasma, con la finalidad de experimentar el afecto -forzosamente experimental-y la producción de la ficción" (2010: 11). Por su lado, Sergi Sánchez, en su estudio sobre Gilles Deleuze y el cine contemporáneo, Hacia una imagen no-tiempo, se sirve también de Mulholland Drive en diálogo con Vértigopara marcar un punto de ruptura entre la modernidad y el cine contemporáneo. Para él, se trata de un desplazamiento de la mirada de un demiurgo masculino a un deseo femenino, sin leyes de espacio y de tiempo y donde "todo es confusión y caos" (Sánchez, 2013: 94-95). Más allá de tratarse de dos películas de referencia dentro de la historia de la crítica cinematográfica, ¿de dónde surge la asociación entre ambas? ¿En qué medida podemos afirmar que Mulholland Drive transforma ciertas ideas sobre el cine moderno que venían representadas en el film de Hitchcock? Y si, según Delorme, Mulholland Drive ha creado un nuevo paradigma, ¿qué ideas estéticas del film de Lynch resurgen en otras propuestas contemporáneas?

Para responder a estas preguntas, partiremos de los estudios sobre cine de Deleuze, quien sitúa la obra de Alfred Hitchcock en la encrucijada entre el cine clásico y el moderno, esto es, entre la imagen-movimiento y la imagen-tiempo ${ }^{2}$. Para Deleuze, el paso de un sistema al otro arranca con la ruptura del vínculo sensoriomotor del personaje. La amnesia de John Ballantine en Recuerda (Spellbound, 1945), la fractura en la pierna de Jeff en La ventana indiscreta (Rear Window, 1954) o la acrofobia de Scottie en Vértigo imposibilitaban una acción por parte del personaje, este se encontraba frentea una incapacidad y quedaba relegado a un rol de espectador. A partir de aquí, nace lo que Deleuze define como imagen-mental, y se produce el paso entre un cine de acción y el cine de videncia que predomina en gran parte de la modernidad: desde el cine de Jean Renoir, Roberto Rossellini o Federico Fellini a la obra de Alain Resnais, Jacques Rivette o Marguerite Duras. ¿Qué lugar ocupa Mulholland Drive dentro de las tesis de Deleuze, de la tradición de la imagen-tiempo y, en particular, de las cuestiones que ya planteaba Vértigo? Esto es lo primero que deberemos intentar resolver.

Sobre la relación entre ambos sistemas y la ruptura histórica entre el clasicismo y la modernidad ver: Rancière, Jacques. “¿De una imagen a otra? Deleuze y las edades del cine”. La fábula cinematográfica. Reflexiones sobre la ficción en el cine. Barcelona: Paidós, 2005, pp. 129-146. 


\section{De Vértigo a Mulholland Drive, o de la mirada al deseo}

Viridiana (Luis Buñuel, 1961), La Jetée (Chris Marker, 1962), La sirena del Mississippi (La Sirène du Mississipi, François Truffaut, 1969), Solaris (Andréi Tarkovsky, 1972), Fascinación (Obsession, Brian de Palma, 1976) o La cautiva (La captive, Chantal Akerman, 2000) son tan solo algunas de las grandes películas de la historia del cine que toman la referencia de Vértigo. El argumento del film de Hitchcock es conocido: Madeleine -Kim Novak- ha adoptado la identidad de una antepasada suya, Carlota Valdés, y Scottie -James Stewart-, un detective retirado por padecer acrofobia, debe ayudar a recuperar su identidad. ¿A partir de qué momento Scottie, punto de vista del espectador, empieza a entrar en el universo de Madeleine? Según el argumento de Sánchez, es aquí donde encontramos una primera diferencia con respecto a la propuesta de Lynch.

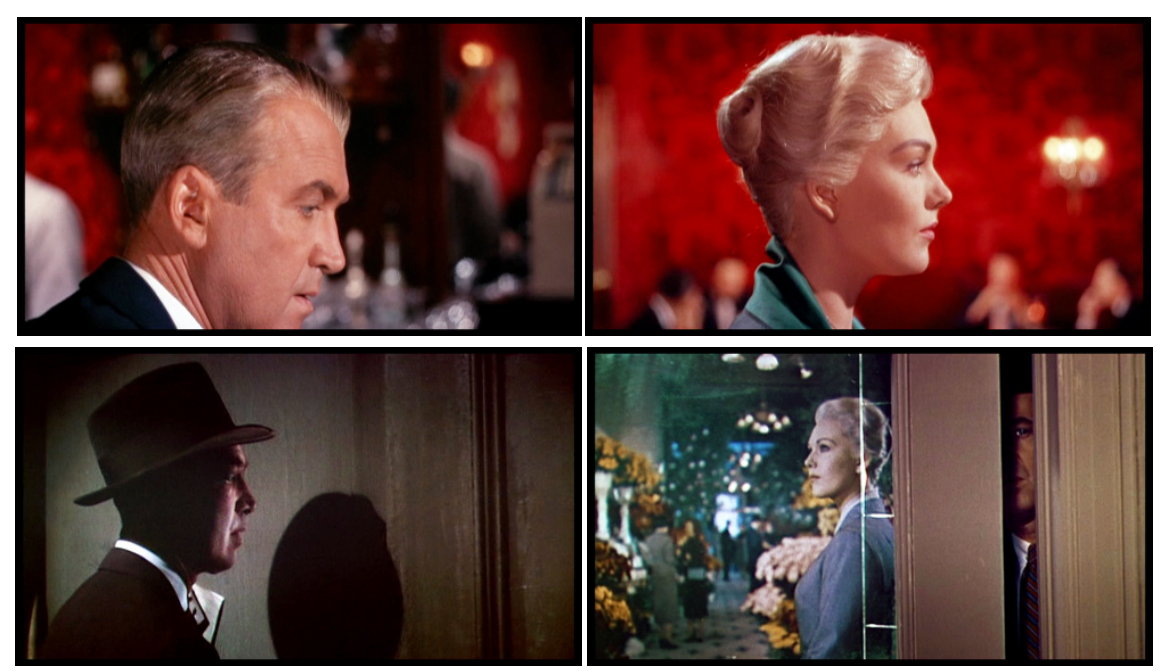

Imagen 1. La primera y la segunda "mirada" de Madeleine.

Vértigo, Alfred Hitchcock, 1958. [Fuente: captura de pantalla]

Tras ver a Madeleine en el restaurante, el seguimiento de Scottie se desarrolla desde una lejanía que le permite estar cerca de Madeleine sin ser visto por ella. Esta lejanía se mantiene hasta el intento de suicidio de Madeleine. Sin embargo, ya antes presenciamos dos "miradas" entre ambos. La primera se produce en el restaurante, poco después de que Scottie la vea por primera vez, en un intercambio de planos que no obedece al plano/contraplano clásico, sino a un encuentro entre dos perfiles que parecen mirarse gracias al crescendo del leitmotiv musical de Bernard Hermann y, sobre todo, al cambio de luz en el rostro de Madeleine que "positiviza" la imagen y la define como el fantasma en el que se convertirá para Scottie-imagen 1-. A partir de aquí, Scottie recupera la distancia, empieza a seguirla en coche hasta que Madeleine entra en una floristería. Allí se produce la "segunda mirada", cuando Madeleine se dirige al espejo y vemos a ambos personajes en el mismo cuadro: Madeleine frente al espejo junto a la puerta por donde la mira Scottie. Las palabras de Didi-Huberman en Lo que vemos, lo que nos mira podrían explicar esta experiencia: "En el momento en el que lo que vemos empieza a ser atrapado por lo que nos mira [...] se 
abre el antro cavado por lo que nos mira en aquello que vemos" (1997: 47). Este antro es aquí la sala obscura por la que mira Scottie, metáfora de la cámara obscura y de la sala de cine, lo que explica que Scottie encarna el lugar del observador -quizás también del creador de la imagen que ve- y Madeleine, el de la imagen. Pero Didi-Huber añade también que, "cuando lo que vemos empieza a ser atrapado por lo que nos mira", entramos entonces en una experiencia ya no de distancia, sino de tiempo. Es lo que ocurre en Vértigo a partir de esa "segunda mirada": entramos a conocer el pasado de Madeleine, la tumba de Carlota Valdés y la pérdida de un origen en el orden cronológico. Porque, tras la muerte de Madeleine, el pasado dialogará con el futuro de Judyy Madeleine será un fantasma siempre reencarnado. Hitchcock nos introducía de este modo a uno de los lugares favoritos del cine moderno, ese paradigma al que se refería Delorme: el universo fantasmático y el reino de la memoria.
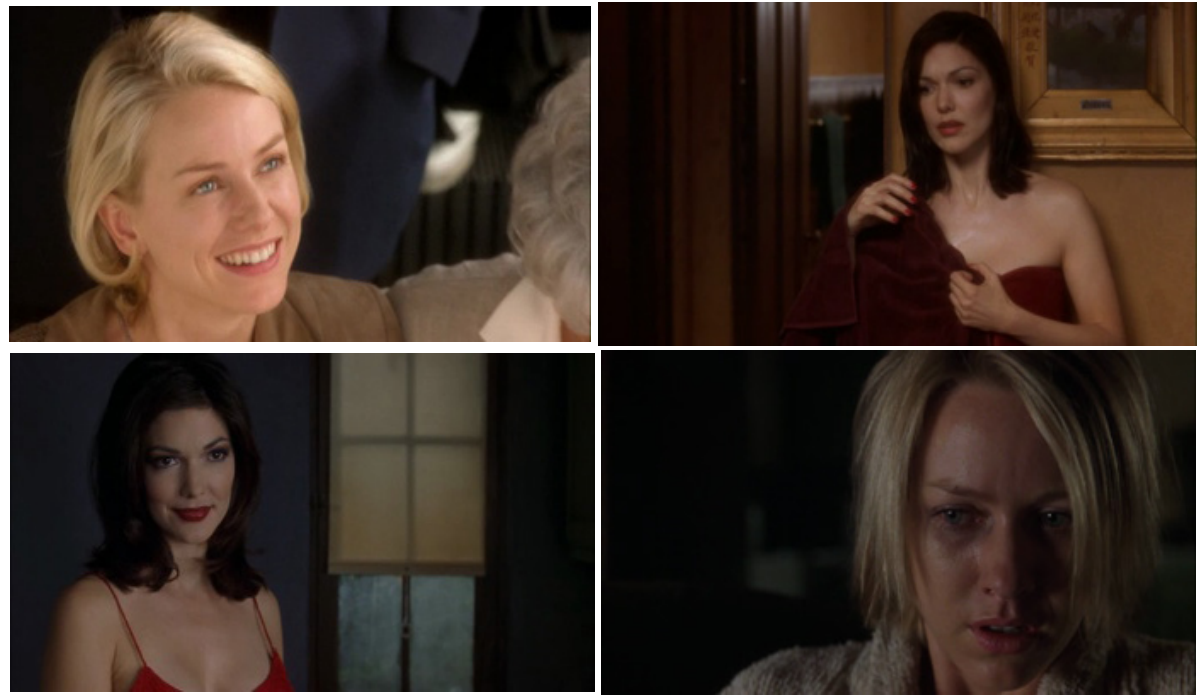

Imagen 2. Las relaciones espejadas de Betty/ Diane Selwyn y Rita/Camilla Rhodes. Mulholland Drive, David Lynch, 2001. [Fuente: captura de pantalla]

A priori, Mulholland Drive sigue un esquema similar: Rita - Laura Harring-sufre un accidente y parece que ha perdido la memoria. Entra en una casa vacía y allí llegará Betty -Naomi Watts-, una jovencita que quiere triunfar en Hollywood. La tarea de Betty consistirá en ayudar a Rita a reencontrar su identidad. Sin embargo, a diferencia del film de Hitchcock, sumergirse en la memoria no supone tan solo un viaje hacia la muerte, ni el fantasma es capaz de aparecer como imagen del otro solamente, pues el encuentro entre ambas miradas se da, como en Persona-Ingmar Bergman, 1966-, a través de una simbiosis que emerge la noche en la que Rita cree recordar algo, una frase -"no hay banda"-, y un lugar al que dirigirse: el Club Silencio. Una simbiosis, o más exactamente, la imagen de dos dobles en dos relaciones espejadas, pues a partir de este momento, la una se convierte en la otra, pero Rita es -también-Camilla Rhodes y Betty es -también- Diane Selwyn -imagen 2-.

Después de entrar en el Club Silencio, Rita abre una caja azul y, a partir de este momento, ya no sabremos quién es la creación de quién, ni si lo que vimos en la primera parte de la película debemos tomarlo como referencia, pues la segunda parte, 
más corta, más imprecisa y, a priori, más alejada del mundo real, parece que explique la primera: que todo lo que vimos fue el sueño que Betty persiguió para convertirse en actriz de Hollywood (Fuller, 2001: 14-17). Según esta tesis, Lynch nos situaría a partir de este momento en la "realidad" de Betty, cuyo nombre es ahora el de Diane. Sin embargo, esta "realidad" se presenta como una imagen de relación con los rostros y lugares que ocupaban la primera parte de la película, como si el sueño de Betty en la primera parte hubiera creado un agujero en la "realidad" de Diane y esta fuera incapaz de discernir en qué mundo pertenece. Porque la referencia aparece modificada, desplazada. En Mulholland Drive no hay un campanario, escenario en el que todo acaba y vuelve a empezar en Vértigo; no hay por lo tanto una posibilidad de retorno concreto; no hay tampoco lugares o motivos que nos sitúen frente al recuerdo -un lienzo, un hotel, una tumba, un ramo de flores en Vértigo-; no hay un tiempo concreto al que regresar, y la posibilidad de especular sobre ese tiempo no parece existir. Y, finalmente, no existe tampoco en el film de Lynch una mirada de partida, como la de Scottie: porque el sujeto, como dijimos, en simbiosis y desdoblado, también falta.

Sergi Sánchez se refiere a esta pérdida del marco referencial y, para ello, se refiere a un desplazamiento entre Vértigo y Mulholland Drive. Si la película de Hitchcock consiste en la experiencia de una mirada masculina -Scottie- en busca de la identidad del otro -Madeleine-, en el film de Lynch el sujeto masculino es pasivo, encarnado por Adam, el cineasta que obedece a las leyes de Hollywood, -alter ego de Lynch, interpretado por Justin Theroux- y toda la inquietud arranca en el encuentro entre las dos protagonistas, no desde la distancia, como ocurría en la aproximación de Scottie a Madeleine, sino desde el deseo. Según Sánchez, el encuentro sexual entre Rita y Betty anticipa la apertura de la caja que, asociada al mito de pandora, tendrá "reminiscencias excesivas y destructoras". En efecto, es después del encuentro sexual entre ambas que Rita parece recordar algo, que la simbiosis entre ambas empieza y que la cámara penetra en un lugar del que deberán emerger nuevas imágenes. Desde esta óptica, el deseo, en Mulholland Drive, provoca la ruptura de toda referencia; representado por el interior de la caja azul, el deseo es "un agujero que devora tiempo y espacio, el amor en todas sus formas" y, bajo sus redes, "estamos alejados del reino del Logos, y metidos de lleno en el reino de Eros, donde todo es confusión y caos" (Sánchez, 2013: 95).¿Qué lugar ocupa la memoria dentro de este reino? ¿Cuál es la experiencia de tiempo del sujeto en un film en el que todo es "caos y confusión"? En definitiva, ¿de qué forma la pérdida del marco referencial del espacio-tiempo de Mulholland Drive entronca con las ideas que Deleuze desarrolló en la imagen-tiempo?

\section{La pérdida (de la memoria) del sujeto}

Como explicamos en la introducción, Hitchcock acerca la imagen-movimiento del cine clásico a la imagen-tiempo del cine moderno. En sus películas, dice Deleuze, la crisis sensoriomotora del personaje produce una incapacidad de la acción y, sujetas a esta incapacidad, las imágenes ofrecen nuevas lógicas de encadenamiento, nuevas formas de abordar lo visible, de pensar las imágenes: el "cine de videncia" reemplaza el "cine de acción" de la imagen-movimiento. En concreto, Deleuze se sirve de Vértigo para adentrarse en uno de los temas centrales de la modernidad cinematográ- 
fica como es la relación que el sujeto establece con el tiempo y con la memoria. Vértigo nos sitúa delante de la experiencia proustiana de que el ser humano es interior al tiempo y no al revés, nos enseña "cómo habitamos el tiempo, cómo nos movemos dentro de él en esa forma que nos lleva, nos recoge y nos ensancha". Deleuze define a partir de aquí la "imagen-cristal", cuando "el tiempo no cronológico" es "captado en su fundación" (Deleuze, 2004: 115). Madeleine encarna esta experiencia para Scottie: su imagen presente convive con el pasado de Carlota Valdés. El film de Hitchcock explica de este modo el "principio de indeterminabilidad, de indiscernibilidad" de la imagen-tiempo, que pone en crisis la distinción entre objetivo y subjetivo, entre real e imaginario, físico y mental (2004: 19), entre la imagen actual -Carlota Valdés, Judy- y su imagen virtual -Madeleine-.

Mulholland Drive pertenece a la genealogía de esta imagen, a la tradición de un cine interesado en la memoria, marcado por la amnesia, el trauma o el trastorno mental que definen las situaciones dispersivas, elípticas y de nexos débiles propias del aflojamiento sensoriomotor de la imagen-tiempo (Deleuze, 2004: 14). Como dijimos, desde las primeras imágenes, Rita padece amnesia y la película, en cierto modo, arranca con el intento de recuperar su memoria. La película de Lynch hereda la forma de las películas sobre la memoria de Alain Resnais, El año pasado en $\mathrm{Ma}$ rienbad (L'annéedernière à Marienbad, 1962) y Te amo, te amo (Je t'aime, je t'ai$m e, 1968)$, películas cruciales en la definición de la imagen-tiempo y de un cine del cerebro. En estas obras, Deleuze observa un desplazamiento del "centro" o "punto fijo" que permitía el reconocimiento atento de la imagen-movimiento, un encuentro con lo inaccesible cada vez que el personaje intenta sumergirse en su memoria y regresar a la imagen del pasado que le obsesiona.

Domènec Font constata la continuidad que existe entre la modernidad y el cine contemporáneo en el interés por seguir explorando la memoria. Sin embargo, según Font, el film de Lynch, al igual que otras propuestas coetáneas en el cine de autor como Spider -David Cronenberg, 2002- o Un hombre sin pasado -TheManWithout A Past, AkiKaurismäki, 2002-, nos sitúa delante de otro escenario en la medida en que "los personajes, desviados de su trayectoria, [...] no podrán volver a su órbita cuando la historia se cierre en forma de bucle". A pesar de que los personajes de los films citados, también en el caso de Vértigo, no consigan obtener o ver con claridad la imagen que les obsesiona, lo que diferencia Mulholland Drive de esta tradición es que parece que ya no existe una imagen de recuerdo, de obsesión, un lugar de origen al que volver, pues el sujeto ya no cuenta con esta posibilidad: su mirada, como vimos, ha sido desplazada por un deseo que ya no deja ver y que acaba con un espacio-tiempo definido. Porque, siguiendo el argumento de Font, los sujetos "son cuerpos transparentes que nacen con la película y gracias a la cual tendrán la posibilidad de vivir una segunda vida" (Font, 2009: 7). Esta observación nos situaría delante de una posible ruptura con respecto al cine precedente, en la que la pérdida de la referencia ya no depende de la mirada del personaje - de su incapacidad motriz-, pues estamos más bien en el terreno de la enfermedad o la perturbación mental -de la paranoia, el sinsentido, la "locura" (Chion, 2003: 327)- y, en este lugar, parece que son las imágenes, la "producción de ficciones" a la que se refería Delorme, las que definen el destino del personaje.

Las imágenes producidas por Betty en la primera parte de la película proceden de su sueño en Hollywood, lugar imaginario que Lynch no deja de referenciar mediante los géneros y las figuras icónicas que lo crearon: Sunset Boulevard, Rita Hayworth o 
la mafia italoamericana, el western, el musical, el melodrama o el thriller. Pero estas imágenes se convierten en el peor enemigo de Betty cuando se despierta del sueño y las mismas imágenes terminan con la protagonista, que pone fin a su trastorno suicidándose en su cama -la cama de Diane-. Al menos tres películas posteriores al film de Lynch conservan algunos de los rasgos de este esquema: Demonlover (Olivier Assayas, 2002), Pasión, un asesinato perfecto (Passion, Brian de Palma, 2012) y Elle (Paul Verhoeven, 2016). Como en Mulholland Drive, las tres heroínas se ven sometidas a un proceso de subjetivación y de pérdida del control también asociada a un deseo entre mujeres. Por otro lado, las tres mantienen una estrecha relación con el mundo virtual: Michèle -Isabelle Huppert- es productora ejecutiva de videojuegos, Diane -Connie Nielsen- es la responsable de un proyecto de cine porno anime e Isabelle -Noomi Rapace- trabaja como creativa audiovisual en publicidad. Las ficciones en las que trabajan las heroínas funcionan en estos films como la industria del cine y la fábrica de sueños de Hollywood en Mulholland Drive y en Inland Empire (David Lynch, 2006): el lugar de una ambición que termina escapando al control del sujeto y en el que la heroína solo puede permanecer desorientada porque su destino ya no le pertenece a ella o, al contrario, persiguiendo un sueño a lo largo de la película no ha hecho más que construir su propia muerte.

Si el deseo abre la puerta a la pesadilla y a la pérdida de un espacio-tiempo definido, en estos films, las ficciones toman el control del sujeto para dirigirlo hacia un lugar que no parece ser otro que el del engaño, el del juego. En su monografía sobre el cineasta, Michel Chion hace referencia a ello: "Lynch juega "con" el cine -y no "al" cine- como con un juego infantil del que probase, con una ávida curiosidad, sus poderes" (Chion, 2003: 327) y si, según el teórico, la grandeza de Mulholland Drive reside en su "desastre simbólico", es porque en este se produce el contrato entre el film y el espectador. De este modo lo describe Thierry Jousse en el trabajo que dedica a Lynch: la película convierte las imágenes en "trampas que constituyen el motor mismo del film" y sin las cuales "el contrato fundamental entre la película y el espectador no existiría” (Jousse, 2010: 84). Y Aurélie Ledoux parte de este contrato cuando analiza Mulholland Drive en el contexto de un cierto cine americano contemporáneo como el de David Cronenberg, David Fincher, Brian de Palma, Paul Verhoeven o Christopher Nolan. La tesis de Ledoux es que, como en el juego de profundidades de la pintura barroca, en parte de los films de estos cineastas opera un trampantojo (trompe-l'oeil) cinematográfico y este, motor narrativo y asignificante en sí mismo, genera un gusto por la confusión, creando, al mismo tiempo, un goce particular en el espectador. Lo que ofrece este cine es una tensión, en palabras de Ledoux, "entre lo sensible y lo narrativo", por un lado, y "entre el guion fantasmático y la necesidad de la peripecia", por el otro (2012: 186). Esto es, una tensión entre los afectos generados por trampas al espectador y las construcciones narrativas del cine clásico y moderno.

\section{Hacia una "lógica de la sensación": del régimen fractal de la estructura rizomática a la Figura}

En Mulholland Drive, abrir la puerta del deseo significa abrir la puerta a la pesadilla y esto supone un proceso de desfiguración de las imágenes construidas por el sueño 
de Betty. A partir de la interpretación de los sueños de Freud, Jean-François Lyotard se interesó por la relación que el deseo mantiene con el discurso en términos de desfiguración. Porque, para Lyotard, "el deseo no habla, viola el orden del habla" y esta "operación de transgresión" busca la "trascendencia del ver" (Lyotard, 1979: 245, 75). La ruptura del marco referencial en el film de Lynch busca este gesto de trascendencia y, según Sánchez, encuentra respuesta en un comportamiento rizomático que "se extiende y se repliega para volver a nacer, avanza y se retira como la marea" (2013: 98). De nuevo, el término proviene de Deleuze -y de Félix Guattari-, quienes definieron el "rizoma" como la estructura fundamentada por "un modelo que no cesa de constituirse y destruirse" y un "proceso que no cesa de extenderse, interrumpirse y recomenzar", porque su finalidad es instaurar una lógica que derribe el fundamento, la ontología, el comienzo y el fin de las cosas para privilegiar el espacio del entre, de lo que está en medio (Deleuze, 2014: 58-59, 68).
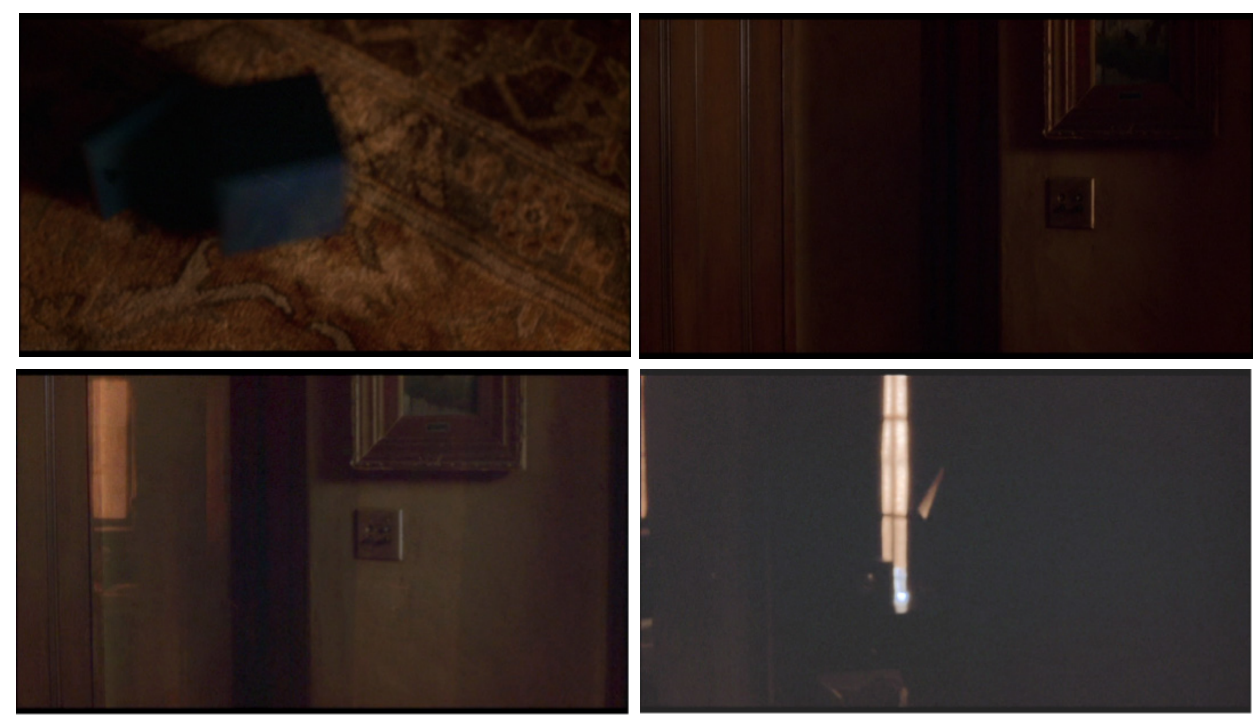

Imagen 3. Imagen rizomática tras la caída de la caja azul y antes del despertar de Betty/ Diane. Mulholland Drive, David Lynch, 2001. [Fuente: captura de pantalla]

Lynch parece mostrar esta imagen rizomática-imagen 3- después de que caiga la caja azul al suelo y antes de que Betty/Diane se despierte: entramos entonces en una confusión de espacios entre la habitación, el pasillo y la cabaña de Diane, imágenes que empezamos a ver y que se desvanecen antes de su reconocimiento, al mismo tiempo que parecen encarnar las múltiples capas o niveles de espacio-tiempo que conforman la película. Siguiendo con las ideas de la imagen-tiempo, la estructura rizomática se plantea desde el encadenamiento entre imágenes mediante "cortes irracionales"; pero en Mulholland Drive ya no se trata de "fragmentaciones reencadenadas", como en el cine de Resnais o del primer Godard, sino que aparece una renuncia al encadenamiento, ambición última de la imagen-tiempo, porque "hemos cesado de creer" en "un prolongamiento real o posible capaz de constituir un mundo exterior", en consecuencia, "la imagen queda separada del mundo exterior" (Deleuze, 2004: 366). Este régimen de imagen entronca con las consideraciones que Deleuze hace en las conclusiones de su segundo volumen en torno a la imagen electrónica-digital: 
"imágenes [que] ya no tienen exterioridad (fuera de campo), y tampoco se interiorizan en un todo: poseen más bien un derecho y un revés, son reversibles y no superponibles, tienen algo así como el poder de volverse sobre sí mismas. Son objeto de una reorganización perpetua donde una nueva imagen puede nacer de cualquier punto de la imagen precedente" (2004: 352).

En la lectura también deleuziana del cine de Lynch, Sonia Rangel parte de la imagen electrónica-digital para concebir lo que denomina como "imagen-fractal": esta imagen se diferenciaría de la imagen-cristal en que, si esta suponía la reversibilidad entre lo actual y lo virtual, "en la imagen-fractal lo que surge es una 'imagen virtual pura' en la que se ponen en juego las potencias de lo falso" (Rangel, 2015: 15).De este modo lo matiza Rangel más adelante:

El surgimiento del régimen fractal supondría la liberación de lo virtual que no se actualiza, que no tiene referencia ni sentido; la imagen-fractal es su propia realidad puramente virtual, la que no se encadena sino que desencadena efectos al conectarse a otras imágenes de manera aleatoria, dando lugar a una serie de imágenes-fractales; montaje y serie que ya no tienen que ver con la descripción ni con la narración, sino con el non-sens, con el quebramiento y la violentación del sentido común (Rangel, 2015: 17).

Surgida de la transgresión, de su voluntad de desarticulación del modelo rizomático, la imagen-fractal consiste en acentuar la fisura entre lo visual y lo sonoro para hallar una correspondencia desde la no-reconciliación entre las imágenes. "Palabras, gritos, ruidos, música [...] conforman una imagen sonora de cuyo ensamble brota la imagen-fractal como imagen-ficción, sin semejanza, sin parecido, siendo autorreferencial", formando "líneas de fuga de una máquina de guerra que se opone a la máquina de interpretación". Si, para Rangel, existe un "carácter legible” en estas imágenes, este se alcanza desde la fractura, desde los efectos desencadenados y generando lo que Deleuze denominará una "lógica de la sensación" ya no sometiendo el tiempo al movimiento entre las imágenes -imagen-movimientoni creando un movimiento a partir de una experiencia de tiempo-imagen-tiempo-, sino a partir de los niveles de sensación en los que "no hay diferencia entre lo real y lo virtual, pues lo virtual aparece como una forma de lo real" (Rangel, 2015: 1819). Es dentro de una "lógica de la sensación" que podríamos explicar entonces que en Mulholland Drive el sueño de Betty en la primera parte del film parezca más cercano a la realidad que la pesadilla de la "realidad" de Diane en la segunda parte del film.

Deleuze se adentra a la "lógica de la sensación" a partir de la pintura de Bacon. En las obras del pintor irlandés, detecta que "la pintura debe arrancar la Figura a lo figurativo" y esta Figura es el cuerpo aislado de todo contexto, de toda historia, de todo significado; lo que da forma a la Figura es "el cuerpo deformado que se escapa", añade (1984: 18). Lo expresan las sombras de Bacon, que se erigen como cuerpos que huyen del cuerpo que representan; o los gritos, resonancias de un cuerpo que se escapa entero por la boca. El pintor exploraría de esta manera las fuerzas del cuerpo y, en esta exploración, para Deleuze, emerge la sensación como ritmo, como un tiempo no-cronológico: "En resumen, no es el movimiento lo que explica los niveles de sensación, son los niveles de sensación que explican lo que subsiste de movimiento" (1984: 31). 
La relación entre la pintura de Bacon y el cine de Lynch no debe extrañarnos, pues como ha reconocido el cineasta en algunas ocasiones, el pintor irlandés formaría parte de su universo de referencias estéticas, dando lugar a imágenes concretas, como el rostro del personaje de El hombre elefante (1980) o la habitación roja de Twin Peaks (1990). Sin embargo, es en el pensamiento de la Figura donde el cine de Lynch parece encontrar una aproximación estética similar a la del pintor. Los niveles de sensación a los que se refiere Deleuze explican, quizás, los niveles o capas de imagen que contiene Mulholland Drive y que, como vimos, Lynch muestra después de la apertura de la caja azul. Son imágenes que relacionábamos con la estructura rizomática, una estructura que Deleuze identifica con una escritura de entre las cosas, pero también con el "sitio por el que las cosas adquieren velocidad" (Deleuze, 2014: 69). En la pintura de Bacon, este ritmo de la sensación, de creación de velocidades, nace, según el filósofo francés, del carácter sintético de la materia, de la "sensación acumulada", "coagulada"; un ritmo que arranca en la materia misma y que encuentra la sensación en el "devenir sensible" (Deleuze, Guattari, 1993: 179), en su proceso de creación, lo que Lyotard definió bajo el término de "figural". Lo "figural", según Lyotard, crea una movilidad del orden de las cosas y no del tiempo, operando como el trabajo negativo de la escritura que pone en relación lo inconexo del texto. Como vimos, mediante este trabajo de movilidad del orden, la Figura no obedece al sentido, sino al deseo. En otras palabras, lo figural sería el campo de fuerza de un deseo que no interpreta, sino que crea un caos, desfigura el sentido lógico y traviesa la obra, para situar la figuración, en palabras de Jacques Aumont, en un lugar en el que "no hay más que proceso, dinámica incesante e interminable" (1996: 168).

La reflexión sobre la Figura como nuevo "orden" de lo visual parece reivindicarse en el cine de autor fundamentalmente americano, pero no exclusivamente. ${ }^{3}$ Como constata Cyril Béghin en el mismo dossier de Cahiers du cinéma con el que abríamos estas páginas, el salto al espacio o a universos paralelos no es solo una marca de los blockbusters, sino que el cine de autor contemporáneo lo ha convertido en una regla con la que crear y en la que "los relatos se condensan, se alinean de arriba abajo y de abajo arriba, y a menudo, se aceleran" y "las inversiones psicológicas, morales y las transformaciones físicas no se reservan al clímax, sino que dan el ritmo general al film" (Béghin, 2010: 13-14). Esta observación entronca con lo que veníamos diciendo, la tendencia de un cine que privilegia un ritmo de la sensación que desfigura y disuelve lo figurativo, y donde la imposición de otros mundos funciona como la Figura en la pintura de Bacon, que busca un lenguaje en el mismo proceso de creación. En la obra del pintor irlandés, Deleuze observa cómo el ritmo de la sensación funciona como una Fuerza "casi invivible" de un Cuerpo sin Órganos que renuncia a la estructura del organismo. "La unidad del ritmo, en efecto, sólo podemos buscarla allí donde el ritmo mismo se sumerge en el caos, en la noche, y donde las diferencias de nivel son perpetuamente removidas con violencia" (Deleuze, 1984: 33). He aquí la estructura de la Figura, formada por lo que Deleuze denomina "diagrama", que introduce una "posibilidad de hecho", una "catástrofe" de lo figurativo y de lo probable y, por consiguiente, la intrusión de otro mundo en la imagen:

Sobre las mismas cuestiones en el cine francés contemporáneo, véase: Vilaró Moncasí, Arnau (2017). La caricia del cine. La invención figurativa de la Nouvelle Vague. Santander: Shangrila, 254-257. 
El diagrama es un caos, una catástrofe, pero también un germen de orden o de ritmo. Es un caos violento en relación a los datos figurativos, pero es un germen de ritmo en relación con el nuevo orden de la pintura: "abre terrenos sensibles", dice Bacon. El diagrama termina el trabajo preparatorio y empieza el acto de pin$\operatorname{tar}$ (1984: 67).
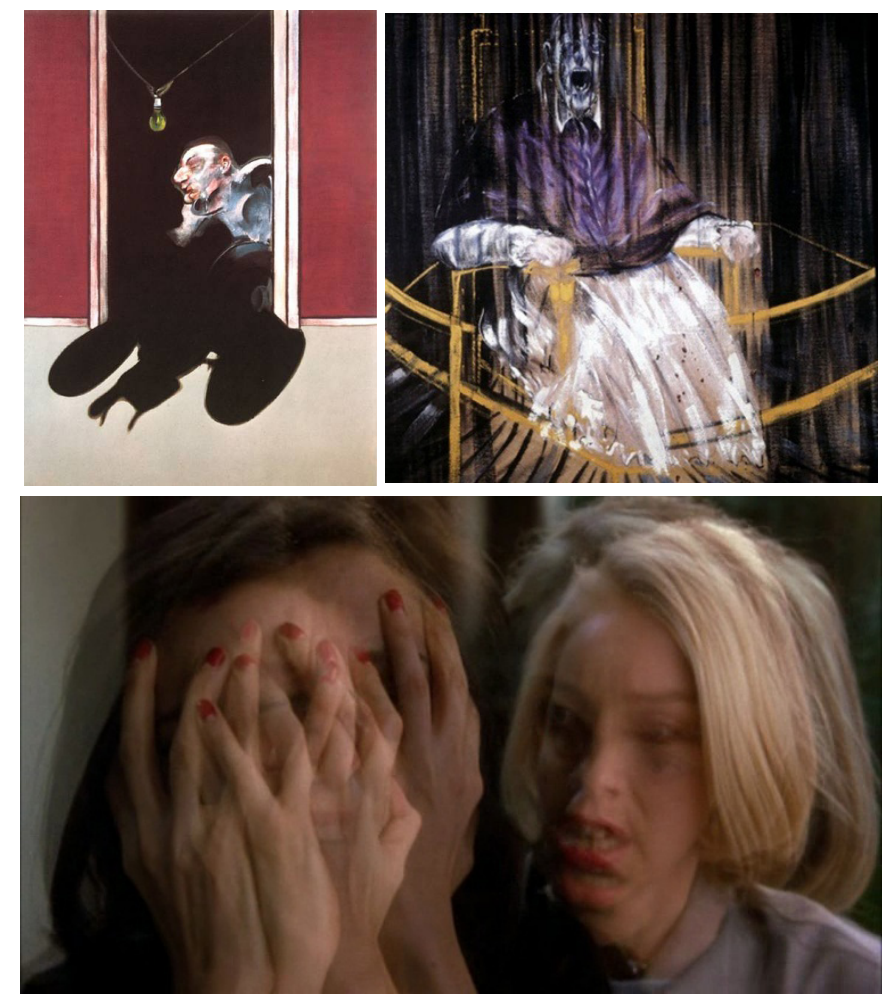

Imagen 4. La imagen como diagrama. Tríptico "Mayo-Junio" (Triptych "May-June”, Francis Bacon, 1973) / Estudio sobre el retrato del papa Inocencio X de Velázquez (Studyafter-

Velázquez's Portrait of PopeInnocent X (Francis Bacon, 1953) / Mulholland Drive

[Fuente: captura de pantalla]

StéphaneDelorme apunta a esta catástrofe cuando se refiere a lo que une la obra de Lynch con otros films de referencia de la primera década del siglo XXI como Elephant -Gus Van Sant, 2003- o incluso Tropical Malady-Apichatpong Weerasethakul, 2004-: "todos estos films tienen en común que están atravesados por una catástrofe, como si todo estuviera ya perdido y que no quedara más que dejarse afectar" (Delorme, 2010: 11).Y en Mulholland Drive, la imagen-diagrama toma forma en la superficie de la imagen después de que las dos heroínas vean el cuerpo podrido de Diane Selwyn, que no es más que la propia muerte de Betty -y también de Rita en tanto que es el otro lado de Betty-(Fig.4): la visión las supera, quizás estamos al lado de la trascendencia de la visión a la que se refiere Lyotard, el caso es que, frente a lo que ven Rita y Betty, no hay figuración posible. Pasaremos entonces a otro lado, a otra ficción, porque en este nuevo cine, escribe Béghin, "las figuras traviesan los mundos" (2010: 14). Estamos lejos, por tanto, de la expe- 
riencia - de personaje- y de la referencia -en el espacio y en el tiempo-, estamos más al lado de un fenómeno que adviene por la pérdida de todo ello, que pone en crisis la narración, también la búsqueda de una visibilidad, y por eso se trata de un fenómeno fundado en la violencia, como lo figural que, para Lyotard, debe pensar lo visible alejado del orden del texto.

\section{A modo de conclusión}

Al inicio de estas páginas, nos preguntábamos acerca del nacimiento de un nuevo paradigma en el cine contemporáneo a partir de Mulholland Drive y de cómo este había desplazado el lugar que, para el cine de la modernidad, había ocupado Vértigo. Vimos cómo este desplazamiento viene provocado por un cambio en los términos que definen la experiencia de la mirada. Sujeta esta al tiempo de la revelación del otro en el film de Hitchcock, en Mulholland Drive tiene lugar la exploración de un deseo que invita a entrar en un universo donde gobierna la pérdida de la referencia temporal, espacial, pero también del sujeto. Siguiendo el interés de la imagen-tiempo en torno a la creación de relaciones entre imágenes a partir de "cortes irracionales", cierto cine contemporáneo nos sitúa frente a una nueva lógica que ya no responde a la imagen-cristal, sino más bien a una estructura rizomática en la que reina una imagen "imagen-fractal" (Rangel, 2015) en la que deja de existir la reversibilidad entre lo actual y lo virtual y el film se abre a "imágenes virtuales puras". Esto explicaría lo que Domènec Font (2009) identifica como el abandono a una idea de retorno a un origen y donde el destino del personaje depende de las ficciones que el film plantea.

A partir de Mulholland Drive, películas como Demonlover, de Oliver Assayas, Passion, de Brian de Palma, o Elle, de Paul Verhoeven, plantean motivos similares a los del film de Lynch: el deseo como forma de subversión, la relación con lo virtual como entrada a nuevas imágenes y la asunción de la violación o la pérdida del control del personaje. Películas, todas ellas, travesadas por una idea de catástrofe y que el film no se deja más que afectar por ella. El término "Figura", con el que Deleuze piensa la pintura que desprende de lo figurativo, explicaría la naturaleza de estas imágenes. Imágenes que someten el movimiento y el tiempo a la sensación -lo que Deleuze denomina "lógica de la sensación"-, o a lo que Delorme expresa como la "experimentación de afectos". ¿Ha abandonado este cine su interés por el fantasma y la memoria? Es difícil responder todavía a esta pregunta. Sin embargo, los distintos niveles de imágenes que conforman la película, provocada en gran parte por la proliferación de imágenes en la sociedad contemporánea, apunta hacia una transformación. En Mulholland Drive encontramos una afectación de los tres ejes centrales en la creación de la lógica del cine clásico y moderno a partir de Deleuze: la acción -sensoriomotor o desplazada a una forma de videncia en la situación del personaje-, la mirada - marcando una dirección en la correspondencia de planos o abriendo la imagen a nuevas subjetividades-y la realidad-realismo orgánico en el cine clásico o ambiguo en el cine moderno-. Entrar en el universo del deseo supondría entrar en un simulacro que ha perdido el orden simbólico y, este "nuevo orden", el de la Figura, se deleita en una creación de afectos que surge de la pérdida de lo simbólico, de un enfrentamiento al caos que no crea conceptos, como la filosofía, ni funciones, como 
la ciencia, porque "el arte lucha con el caos, pero para hacerlo sensible" (Deleuze, Guattari, 1993: 205). Se trata, en definitiva, de la lógica de una sensación surgida de una forma de escritura que privilegia el proceso de desfiguración y que el espectador vive en el visionado mientras sigue buscando, entre los trampantojos de la película, los vestigios de cualquier interpretación.

\section{Bibliografía}

Aumont, J. (1996). À quoipensent les films? París: Seguier.

Béghin, C. (2010). "Des récits en lacets", dossier "Les meilleurs films des années 2000". Cahiers du cinéma, núm. 652, 13-14.

Chion, M. (2003). David Lynch. Barcelona: Paidós.

Deleuze, G. (1984). Francis Bacon: logique de la sensation. París: Différence.

Deleuze, G. (2004). La imagen-tiempo. Estudios sobre cine 2. Barcelona: Paidós.

Deleuze, G.; Guattari, F. (1993). ¿Qué es la filosofía? Barcelona: Anagrama.

Deleuze, G.; Guattari, F. (2014). Rizoma. México: Fontamara.

Delorme, S. (2010). "Une décennie lyrique", dossier "Les meilleurs films des années 2000". Cahiers du cinéma, núm. 652, 10-11.

Didi-Huberman, G. (1997). Lo que vemos, lo que nos mira. Buenos Aires: Manantial.

Font, D. (2009). "En las redes del tiempo". Formats: revista de comunicació audiovisual, [en línea], núm. 5, https://raco.pre.csuc.cat/index.php/Formats/article/view/136941 (Consulta: 23-09-2020).

Fuller, G. (2001). "Babes in Babylon”, vol. 11, núm. 12,Sight and Sound, 14-17.

Jousse, T. (2010). David Lynch. París: Cahiers du Cinéma.

Ledoux, A. (2012). L'ombre d'un doute. Le cinéma contemporain et ses trompe-l'œil. Rennes : PUR.

Lyotard, J. F. (1979). Discurso, Figura. Barcelona : Gustavo Gili.

Rancière, J. (2005). La fábula cinematográfica. Reflexiones sobre la ficción en el cine. Barcelona: Paidós.

Rangel, S. (2015). Ensayos imaginarios. Aproximaciones estéticas al cine de David Lynch, David Cronenberg, Béla Tarr y Nicolás Pereda. México: Ítaca.

Sánchez, S. (2013). Hacia una imagen no-tiempo. Deleuze y el cine contemporáneo. Universidad de Oviedo.

Vilaró Moncasí, A. (2017). La caricia del cine. La invención figurativa de la Nouvelle Vague. Santander: Shangrila. 
